\title{
A "DIALÉTICA" HEGELIANA: O PROJETO DE UNIFICAÇÃO DA LÓGICA E DA ONTOLOGIA
}

Maria de Lourdes Borges*

SINTESE - Este artigo propõe-se a apresentar o sistema hegeliano como uma tentativa de unificar a Lógica e a Ontologia. Neste sentido, Hegel radicalizaria a filosofia crítica como aquela que pensa o objeto de conhecimento enquanto constituído pelo sujeito. Mostraremos que, para Hegel, as categorias apresentadas na Ciência da Lógica são categorias do ser e do pensamento sobre o ser. Por fim, exploraremos a noção de exposição da Idéia hegeliana como aquela que desdobra sua idealidade na objetividade mundana.
ABSTRACT - The purpose of this article is to present Hegel's system as an attempt of unifyng logic and ontology. In this sense, Hegel has radicalized the critical philosophy as one thinking the object of knowledge constituted by the subject. We show that, according to Hegel, the categories presented in Science of logic are categories of the being and of the thougth about it. Finally, we shall explore the notion of the exposition of Hegel's Idea as unfolding its ideality in the objectivity of the world.

\section{1 - Ser mais hegeliano que Hegel...}

Hegel, nas Lições sobre a Filosofia da História, ao referir-se a Robespierre escreve: "Este homem levou a virtude a sério"., Ao ler o artigo de Cirne Lima "Dialética e Evolução",** sou levada a uma exclamação análoga: "Este homem levou Hegel a sério". Por que digo isto? Porque Cirne Lima, em que pese dizer-se há muito um ferrenho defensor da contingência, busca, de forma surpreendente, construir um sistema que dê conta da logicidade interna das formações naturais e espirituais. Talvez Cirne Lima vá inclusive bem mais longe do que o próprio Hegel na tentativa de construir um paralelo entre a Lógica e o lógico: ao ler o item referente a natureza e percebendo sua tentativa de vincular a Lógica a uma ciência natural (a Biologia), através de estreitos paralelos, pareceu-me por um momento que ele iria enfim realizar o que o Sr. Krug pediu a Hegel sem sucesso: deduzir a caneta com a qual eu sublinhava seu texto.

Penso que o empreendimento "cirne-limeano" é surpreendente e desenvolve uma intuição, sem dúvida alguma, profundamente hegeliana: a busca desta identidade entre lógos e ser. Considero, todavia, que ele acabou por construir um siste-

* Universidade Federal de Santa Catarina, UFSC.

* Nota do editor: A autora se refere ao $1^{2}$ artigo deste número, p. 701.

\begin{tabular}{|l|l|l|l|l|l|} 
VERITAS & Porto Alegre & v. 40 & $\mathrm{n}^{\circ} 160$ & Dezembro 1995 & p. $779-790$ \\
\hline
\end{tabular}


ma onde o conceito está por demais presente na natureza, deixando, ao contrário de Hegel, ao Espírito a tarefa de ser a abertura à contingência de toda exteriorização. No seu próprio linguajar, ele construiu uma natureza "fechada" demais e um espírito "aberto" em demasia, invertendo neste sentido a pirâmide hegeliana quanto ao acaso e necessidade. A necessidade do lógico é procurado sobretudo no mundo natural, deixando praticamente livre desta necessidade - maneirismos do nosso fim de milênio? - o mundo espiritual.

Quanto a natureza posso afirmar sem susto que Cirne Lima foi mais hegeliano do que o próprio Hegel. Se ele, no decorrer do seu trabalho, estiver algum dia pronto para dar ao Sr. Krug o que idealismo absoluto não pode oferecer - uma dedução das particularidades do mundo natural - trocarei rapidamente minha caneta Bic Metal Point por uma caneta Mont Blanc.

Minha contribuição neste debate faz-se do "humilde" ponto de vista de uma historiadora da Filosofia. Tentarei neste artigo apenas enfatizar um dos temas trazidos pelo artigo do prof. Cirne Lima; qual seja, a relação entre Ontologia e Lógica, procurando mostrar que se trata de uma radicalização do projeto crítico. Pois, ainda que Física pela minha formação acadêmica, posso afirmar que jamais consegui descobrir nenhuma relação entre a Doutrina da Essência e a Mecânica Quântica.

\section{2 - Uma radicalização do projeto crítico}

Na introdução à Ciência da Lógica, ${ }^{1}$ nos é afirmado que o começo da ciência pressupõe a Fenomenologia: "Tomemos pois como ponto de partida, na exposição que se segue, o conceito da ciência pura e sua dedução, visto que nós julgamos que a Fenomenotogia do Espírito não é outra coisa que sua dedução". ${ }^{2}$ Hegel é claro na sua definição: a Fenomenologia deve ser a pressuposição da ciência pura, pois, para que haja ciência pura, é necessário que estejamos livres de "oposição que perturbava a consciência". ${ }^{3}$ A perturbação que é extirpada da consciência por intermédio da Fenomenologia consistia na separação rígida entre o homem que conhece e o mundo a ser conhecido.

Esta é a pretensão hegeliana, em relação à qual a Fenomenologia cumpre um papel central: suprimir a separação entre o sujeito que conhece o objeto e o objeto que é conhecido pelo sujeito. Com isso, Hegel não pretendia negar a existência de coisas materiais que existem no mundo independentemente da percepção humana, mas afirmar que o conhecimento filosófico não deve ancorar-se na separação entre o lógico e o real. A filosofia que almeja denominar-se ciência não pode separar o movimento do mundo do movimento lógico; não deve partir, por conseguinte, de

1 (A referência à obra hegeliana no original alemão será feita conforme a edição Suhrkamp, Werke in 20 Bänder, ed. Moldenhauer / Michel). Existem duas versões da Ciência da Lógica, primeiro tomo, primeiro livro, A doutrina do Ser, a de 1812 e a de 1831. As referências, salvo nota em contrário, serão feitas à segunda, conforme edição da Suhrkamp utilizada, e tradução para o Francês da Aubier, 1947. A tradução para o Francês de Gwendoline Jarczyk e P. J. Labarriére, que será referida quanto aos outros dois livros - A Doutrina da Essência, A Doutrina do Conceito - tomam a primeira edição da Doutrina do Ser (1812) para sua tradução.

2 S. L., I, p. 34; W. L., I, p. 43.

3 S. L., I, p. 35; W. L., I, p. 43. 
um sujeito cognoscente autônomo em relação ao objeto do conhecimento, nem de um objeto independente frente ao sujeito.

Na filosofia de Hegel, Lógica e Ontologia estão interligadas: não é possível uma ontologia enquanto um estudo do ser como algo separado do pensamento. A Filosofia deve tratar do ser enquanto constituído pelo pensamento, no sentido de que a razão contida potencialmente no ser é por ele revelada. Tomados isoladamente, homem e mundo são para Hegel abstrações. A Filosofia, que deve ser um sistema em movimento, visa a unificação entre o sujeito que conhece o objeto - 0 homem - e o objeto - o mundo - que é conhecido pelo sujeito. Para que a ciência seja possível, torna-se necessária a superação, tanto da filosofia anterior, como da atitude ingênua do conhecimento que se ancora numa separação entre o sujeito cognoscente e seu objeto de conhecimento.

Na introdução à Ciência da Lógica, Hegel constata que a Lógica até então era tratada como a disciplina que abstraía todo conteúdo, tratando apenas das condições formais de qualquer conhecimento verdadeiro. Havia uma separação entre, de um lado, a verdade, de outro, a certeza. De um lado, tinha-se a matéria que se encontrava fora do pensamento, como um mundo completo; de outro, tinha-se o pensamento vazio que procurava fora de si algum conteúdo. O objeto era visto como algo auto-suficiente que, como tal, não necessitava do pensamento; o pensamento era uma forma mole que deveria adaptar-se a matéria.

A forma de conhecimento visada pela crítica de Hegel é aquela para a qual a verdade é a adequação da forma ao conteúdo, do pensamento ao objeto, sendo um externo ao outro. Não apenas a dicotomia entre os dois termos é objeto de sua crítica. É principalmente à subordinação do pensamento ao objeto que Hegel se opõe. "Entre estes dois elementos constitutivos (pois sua relação seria de elementos constitutivos cujo conhecimento se comporá, por assim dizer, mecanicamente, ou quando muito, quimicamente) existe um hierarquia tal que o objeto será qualquer coisa de completo, de realizado, que, para ser real, não teria necessidade do pensamento, enquanto o pensamento seria algo de incompleto que, para se completar, teria necessidade de uma matéria e, tal qual uma forma mole, indefinida, dever-seia adaptar à matéria". ${ }^{4}$ Este comentário visa atacar principalmente a concepção de conhecimento verdadeiro como adequação entre o pensamento e o ser, sendo um externo e independente do outro. A idéia de verdade como adequação pressupõe também um desequilíbrio entre os termos: é apenas o pensamento que deve fazer um movimento no sentido de se amoldar ao ser; o ser permanece, no entanto, imóvel na sua verdade. $\mathrm{O}$ objeto apresentaria, portanto, uma autonomia, uma permanência. Ao pensamento, ao contrário, não restaria senão a alternativa de amoldarse ao único elemento considerado subsistente no processo de conhecimento.

Hegel aceitava esta dualidade se vinda do senso comum e procura, inclusive, resgatar a separação feita por este como momento necessário da Fenonenologia para que a consciência chegue ao saber absoluto. A Filosofia, porém, enquanto ciência, deveria superar esta dicotomia. Para tal, a Filosofia deveria renunciar à idéia de verdade como adequação entre o mundo e sua representação e substituir a adequação pela exposição (Darstellung) da coisa-mesma, o que significa trazer à

4 S. L., I, p. 29; W. L., I, p. 37. 
tona a racionalidade do mundo. O processo de exposição, ou apresentação, da coisa mesma implica um movimento de progressiva identificação entre o homem e 0 mundo. Não se trata de forçar a estrutura do mundo a ter a mesma estrutura do entendimento, nem dos conceitos se amoldarem a estrutura do mundo. A proposta hegeliana é uma tentativa de resgate de uma unidade da razão sempre presente no homem/mundo. Neste sentido, é abandonada a idéia de conceito como representação, ele deixa de ser um elemento puramente subjetivo vindo a ser um elemento desta totalidade homem/mundo, tomada na sua pureza. O conceito hegeliano é a estrutura algébrica do mundo, o cerne racional presente em tudo o que é.

Kant, na opinião de Hegel, supera a visão de verdade como adequação do pensamento ao ser. O conhecimento deixa de ser, com Kant, simples representação do ser, assim como os conceitos não são mais apenas suas imagens mentais. Kant introduz, na visão estática de separação e total independência entre pensamento e ser, um elemento de movimento. ${ }^{5}$ Este elemento é a constituição do real pelo sujeito que, através desta operação, lhe confere sentido. O objeto passa a ser, então, não apenas representado, mas constituído pelo entendimento. Para Hegel, entretanto, Kant limita a espontaneidade da razão e do entendimento, limitando, conseqüentemente, a extensão do conhecimento possivel e renunciando ao pensamento especulativo: "A teoria exotérica da filosofia kantiana, de acordo com a qual o entendimento não deve lançar-se além da experiência, pois, se ele o fizer, a faculdade cognitiva tornar-se-á razão teórica, capaz somente de engendrar quimeras, esta teoria, dizemos, fornece a justificação científica da renúncia ao pensamento especulativo". ${ }^{6}$

Se Kant pretendia fazer a crítica da metafísica dogmática, mostrando a impossibilidade da psicologia racional, da cosmologia racional e da teologia racional, o patamar onde chegou, ao limitar a atividade da razão e prescrever apenas um uso regulador e não constitutivo às idéias que aí se engendram, implica a renúncia do pensamento especulativo. É nesse contexto que Hegel lamenta "este povo cultivado privado de metafísica, como um templo magnificamente ornado, mas privado de santuário". Para Hegel, as restrições kantianas apenas o aproximam do senso comum e o afastam de todo e qualquer pensamento especulativo.

Hegel recusa-se de antemão a aceitar esta renúncia. Ao mesmo tempo, diagnostica a base filosófica deste equívoco do pensamento kantiano: a separação entre o objetivo e o subjetivo. Volta, então, à antiga metafísica para resgatar-lhe os fundamentos: "[...] o pensamento e as determinações do pensamento, longe de serem estrangeiros ao objeto, constituem antes sua essência, [...] existe um acordo

5 O elemento de movimento ou de constituição do mundo deve-se ao papel ativo do entendimento admitido por Kant no processo de entendimento: "Nosso conhecimento surge de duas fontes principais da mente, cuja primeira é receber as representações (a receptividade das impressões) e a segunda a faculdade de conhecer um objeto por estas representações (espontaneidade dos conceitos) [...]. Intuição e conceitos constituem, pois, os elementos de todo nosso conhecimento, de tal modo que nem conceitos sem uma intuição de certa maneira correspondente a eles, nem intuição sem conceitos podem fomecer um conhecimento [...]. Sem sensibilidade nenhum objeto nos seria dado, e sem entendimento nenhum seria pensado" - KANT, I. Crítica da Razão Pura, 876, OS PENSADORES, tradução de Valério Rohden e Udo Moosburger, São Paulo, Abril Cultural, 1983, p. 57.

$6 \quad$ S. L., I, p. 5; W. L., p. 13.

7 S. L., I, p. 6; W. L., p. 13. 
entre a coisa e o pensamento, o pensamento nas suas determinações imanentes e a natureza verdadeira das coisas formam um só e mesmo conteúdo". ${ }^{8}$ A filosofia crítica carece, aos olhos hegelianos, deste fundamento da metafísica antiga: a aceitação de uma identidade entre as determinações do pensamento e do objeto.

Se Kant percebeu a atividade constitutiva do sujeito em relação ao objeto, não obteve a superação da dicotomia entre estes dois termos. Para Hegel, Kant ao menos admite a limitação de uma filosofia baseada na separação sujeito/objeto: a impossibilidade do conhecimento da coisa-em-si e a restrição do uso das idéias da razão. Conseqüentemente, uma filosofia que não pretenda restringir o conhecimento não pode se basear naquela separação. Kant, ao aceitar o pressuposto da diferença irredutível entre o homem e o mundo, aceita também pagar o preço devido: haverá sempre no mundo algo não passível de ser conhecido, que toma a forma de coisa-em-si; existirão sempre idéias que não servem ao conhecimento do mundo, as idéias da razão. Kant mantém, assim, um resíduo que Hegel pretende superar. Para este, é inadmissível aceitar a possibilidade de uma parte do mundo que não possa ser penetrada pelo conhecimento, como também o é admitir que as idéias da razão não sirvam ao conhecimento do mundo.

A crítica de Hegel a Kant fica mais clara se analisarmos suas observações no que se refere a toda a arquitetônica kantiana, principalmente na análise das faculdades. Uma das observações de Hegel nos remete à relação entre entendimento e sensibilidade. Para Kant, o conhecimento depende tanto da sensibilidade quanto do entendimento. ${ }^{9}$ Ainda que reconhecendo o papel constitutivo do entendimento sobre a realidade, aquele não pode exercê-lo sem que seja ativado pela sensibilidade, pois os objetos da sensibilidade lhe conferem conteúdo, sem o qual o entendimento é vazio. ${ }^{10}$

Hegel sabia que Kant não era um empirista e que o entendimento kantiano não se constituía num vazio que deveria ser preenchido pelas regras que a natureza fornece pela simples observação. Ao contrário, a natureza, sem a atividade informadora do entendimento, é apenas um conjunto de elementos dispersos que, por si só, não podem nos dar leis ou regras. O entendimento em Kant é vazio no sentido de que ele deve ser ativado pelos objetos sensiveis para que coloque em movimento sua atividade conhecedora. É a esta vacuidade do entendimento e sua necessidade de preenchimento pelas intuições sensiveis que Hegel se opõe, pois isto limita a autonomia do entendimento e o subordina a sensibilidade. Para Hegel, isto implica que o entendimento, por depender da sensibilidade, só nos dá a forma

8 S. L., I, p. 30; W. L., p. 38.

9 "Pensamentos sem conteúdos são vazios, intuições sem conceitos são cegas. Portanto, é necessánio tornar os conceitos sensiveis (isto é, acrescentar-lhes o objeto na intuiçăo) quanto tomar as suas intuições compreensíveis (isto é, pô-las sob conceitos). Estas duas faculdades ou capacidades também não podem trocar as suas funções. $O$ entendimento nada pode intuir e os sentidos nada pensar. O conhecimento só pode surgir da sua reunião" (KANT, op. cit. B76).

10 "Na lógica transcendental, isolamos o entendimento (como acima, na estética transcendental, a sensibilidade) e destacamos do nosso conhecimento apenas a parte do pensamento que tem sua origem unicamente no entendimento. $\mathrm{O}$ uso deste conhecimento puro repousa, porém, na seguinte condição: de que na intuição nos sejam dados os objetos aos quais ele possa ser aplicado. Na ausência de intuição, todo nosso conhecimento carece de objetos, e então permanece inteiramente vazio" (KANT, op. cit. B87). 
do conhecimento verdadeiro, abrindo mão do seu poder criador e ativo. Segundo Hegel, o entendimento kantiano produz apenas conceitos privados de realidade, que só são "ativados" pelo sensível. Ele não possui, para Kant, a autonomia que Hegel pretendia atribuir à razão.

A autonomia da subjetividade é reconhecida por Kant em relação à razão. Esta, na sua espontaneidade, gera idéias que não têm correspondência com os objetos da sensibilidade ${ }^{11}$ Hegel elogia o reconhecimento desta propriedade da razão, mas discorda das conseqüências que Kant daí extrai. Para este, a razão, por ousar ir além do sensível e do finito, perde seu poder constitutivo, as idéias por ela geradas têm apenas um uso regulador. ${ }^{12} \mathrm{~A}$ prova da incapacidade da razão em reconhecer o mundo é dada pelas antinomias da razão na dialética transcendental. ${ }^{13} \mathrm{O}$ uso das idéias da razão com um papel constitutivo gera antinomias. Conclusão de Kant: deve ser vedado o uso constitutivo das idéias da razão. Conclusão de Hegel: o problema não está no uso inadequado dessas idéias, mas no caráter contraditório do mundo do mesmo.

Hegel atribui um papel importante à dialética transcendental, pois, para ele, ela mostra a necessidade da contradição que faz parte das categorias ou determinações do pensamento. "Certo" - nos diz Hegel - "as exposições dialéticas de Kant, nas antinomias da razão pura, não merecem, quando as examinamos de perto [...] grandes elogios, mas a idéia geral, que é a base desta exposição e da qual é necessário ressaltar o valor, e da objetividade da aparência e a necessidade da contradição que, pela sua natureza, faz parte das categorias ou determinações do pensamento". ${ }^{14}$

O lado positivo das antinomias da razão pura, ao enunciar a negatividade interna das determinações, é, segundo Hegel, descobrir o princípio que anima tudo que é dotado de vida espiritual ou natural: a contradição como causa do movimento do que é vivo. A conclusão a que Kant chega é, ao contrário, que a razão é incapaz de conhecer o infinito. Isto significa uma contradição para Hegel, já que o Absoluto (e infinito) é o racional por excelência. Se a razão não pode conhecer o infinito, não há conhecimento do Absoluto, logo, do racional. A conclusão a que chega Hegel é que Kant não aceitaria o passo que deu em direção ao especulativo, que tem como essência exatamente "os contrários como fundidos numa unidade ou 0 positivo como imanente ao negativo". ${ }^{15}$ Para Kant, as antinomias não reproduzem a essência do mundo onde, como queria Hegel, o positivo é imanente ao negativo.

Segundo Hegel, Kant dá um passo atrás, pois limita a atividade da razão e coloca o conhecimento na dependência do empírico, do fenomênico; mesmo admitin-

11 "A denominação de conceito da razão, entretanto, mostra já preliminarmente que ele não quer deixar-se limitar pelo âmbito da experiência" (KANT, op. cit. B368).

12 "Os conceitos da razão servem para conceber, assim como as do entendimento para compreender" (KANT, op. cit. B368).

13 KANT, op. cit. p. 214.

14 S. L., I, p. 42; W. L., I, p. 52. Deve-se ressaltar aqui que as estruturas das antinomias - nas quais Hegel vê uma prova da contradição inerente às categorias - consiste na aplicação a objetos não finitos de categorias cujo espectro de aplicação deve ser composto apenas por objetos finitos, não sendo exatamente uma contradição das categorias, mas uma inadequação da sua aplicação.

15 S. L., I, p. 43; W. L., I, p. 52. 
do que Kant busca as características essênciais, universais e necessárias da experiência, não no sensivel, mas na espontaneidade do pensamento, nos seus elementos a priori, os quais, ao serem ativados pela sensibilidade, produzem conhecimento. Hegel afirma, e este é o motivo central de sua crítica, que Kant tem um ponto em comum com os empiristas: a aceitação da experiência como único campo de conhecimento possível. ${ }^{16}$ Hegel, com esta crítica, não pretende negar a importância do mundo empírico, sua posição não é de um idealista subjetivo para o qual o empírico não contém nenhuma verdade e esta só pode ser encontrada no pensamento. Ele quer apenas ampliar o campo do conhecimento possível, incluindo aí objetos que vão além do sensivel, instaurando uma realidade a ser conhecida que reincorpore os objetos da Metafísica, que foram excluídos daquilo que pode ser conhecido.

A fim de trazer os objetos clássicos da Metafísica ao campo do conhecimento, Hegel atribui um papel constitutivo às idéias da razão. Hegel pretende, conseqüentemente, uma fusão entre entendimento e razão."O entendimento determina e mantém firmemente as determinações; a razão é negativa e dialética, pois ela dissocia e anula as determinações do entendimento; ela é positiva, porque ela cria o geral e apreende o particular. Da mesma forma que o entendimento é concebido como separado da razão em geral, se concebe geralmente a razão dialética como separada da razão positiva. Mas a razão segundo sua verdade é o espírito e o espírito é superior tanto à razão quanto ao entendimento; ele é uma combinação dos dois" ${ }^{17} \mathrm{O}$ entendimento, a razão dialética e a razão positiva são o que Hegel unificou sob o nome de espírito. Suas funções que são, respectivamente, dar as determinações, dissolver estas determinações e criar o geral são momentos de um mesmo processo de conhecimento do mundo. A fusão pretendida não significa que Hegel não esteja atento às funções diferenciadas do que denomina entendimento, razão positiva e razão dialética. Hegel busca uma unificação destas faculdades num termo que denomina de espírito. Desta forma, na Fenomenologia do Espírito, este aparece como a verdade da razão, na medida em que extrapola seu caráter formal. O espírito concede, pois, efetividade à razão. Ao mesmo tempo, é uma superação do momento do entendimento, momento que se constitui numa apreensão ainda limitada do mundo pela consciência.

Pode-se dizer que, tanto para Kant, quanto para Hegel, o entendimento é uma faculdade que tem como objeto entes finitos, enquanto a razão se estende para além desses objetos, por isso ela é infinita. A diferença entre os autores reside na definição de Kant de que a razão concebe, enquanto o entendimento conhece. Os conceitos da razão, denominados por Kant de idéias transcendentais, não possuem conteúdo, pois não se referem a nenhum objeto de sentido, única forma para Kant de ser conferido conteúdo a um conceito. Em Hegel, ao contrário, exatamente por ser a razão infinita, ela conhece. Isto implica, conseqüentemente, um alargamento do conceito de ciência. Ainda que Kant admita a necessidade da concessão de

16 Refiro-me ao conceito de conhecimento tal como Kant expõe na Crítica da Razão Pura, o qual está ligado a experiência sensivel.

17 S. L., 1, p. 8; W. L., p. 16. 
uma realidade objetiva às idéias da razão para uso prático, isto não nos dá uma ciência da ação prática.

Hegel, ao conceber uma razão que conhece, faz com que o conhecimento não seja apenas uma conseqüência da relação do homem frente à natureza, mas também do homem frente a outro homem. Hegel inaugura, então, uma ciência que extrapola o mundo natural e procura dar conta da racionalidade do agir humano. A relação entre os homens, a realidade ética, também estará submetida às regras da razão. Idéias como alma, Deus e liberdade passam a ter cidadania na ciência hegeliana. Ao ampliar a ciência para abarcar tudo o que é racional, são reavivados os objetos da Metafísica que haviam sido banidos de todo conhecimento que se pretendesse denominar científico. Retoma-se a idéia de ciência como sistema total do saber, que vai além da experiência da natureza e abárca todas as construções humanas. Não são racionais apenas as leis que os homens constroem na sua relação com a natureza, mas há uma razão virtual em tudo o que é produzido nas relações entre os homens: os costumes, as leis, o Estado. Este é o sentido da afirmação hegeliana de que "o que é racional é efetivo e o que é efetivo é racional" ${ }^{18}$ Tanto as regras da natureza quanto as regras do mundo espiritual são racionais, podendo, portanto, ser conhecidas. Isto não significa que toda realidade natural, ética, política e social seja racional, mas que se deve buscar o elemento de racionalidade existente na realidade, tanto natural, quanto social.

Se no mundo ético deve estar presente a razão, por sua vez a Ciência da Lógi$c a$, enquanto sistema da razão pura, deve estar sujeita ao trabalho do espírito, pois há um processo de constituição da razão através da História. Se a Lógica pouco mudou depois de séculos, isto não deve ser tido como um ponto positivo desta, mas como prova de sua carência e inadequação. Se a Lógica pouco mudou depois de Aristóteles, isto revela, não sua correção e completude, mas sua inadequação ao seu tempo: "[...] é necessário concluir que ela necessita tanto mais ser modificada, pois o trabalho bi-milenar do espirito deve ter-lhe proporcionado uma consciência mais alta de seu pensamento e de sua pura essencialidade". ${ }^{19}$ Esta crítica à Lógica como algo imutável desde Aristóteles prova para Hegel sua incorreção. Ele se refere ao elogio que Kant faz dessa imutabilidade: "Que a Lógica tenha seguido desde os tempos mais remotos esse caminho seguro depreende-se do fato de não ter podido desde Aristóteles dar nenhum passo atrás, [...]. A Lógica deve a vantagem de seu sucesso simplesmente a sua limitação pela qual está autorizada e mesmo obrigada a abstrair de todos os objetos do conhecimento bem como das suas diferenças, de modo a que nela o entendimento tem que lidar apenas consigo mesmo e com sua forma". ${ }^{20}$

Para Hegel, a Lógica deve ser modificada pelo trabalho do espírito, já que não e algo estático, que segue um formalismo de tipo matemático. Dizer que a Lógica hegeliana não segue o modelo abstrato da Lógica formal não significa afirmar que a Lógica trata da efetividade e da concretude do mundo. A Lógica é o sistema da razão pura: a expressão do Absoluto atemporalizado, no seu puro elemento de ra-

18 "Was vemünfitg ist, das ist wirklich, - und was wirklich ist, das ist vernunftig" - Ph. R., p. 24.

19 S. L., I, p. 37; W. L., I, p. 46.

20 KANT, op. cit., p. 9. 
zão, as categorias do pensamento puro. ${ }^{21}$ Deus (ou o Absoluto) atemporalizado é o que constitui a Idéia hegeliana. O Absoluto, entretanto, não é apenas este puro elemento da razão, mas igualmente todo o processo de exteriorização da Idéia. Este é o objeto da Lógica tal como e expresso na Enciclopédia: "A Lógica é a ciência da Idéia pura, isto é, na Idéia no elemento abstrato do pensamento". ${ }^{22}$

A Ciência da Lógica, nos afirma Hegel, é a ciência da Idéia Pura, e o sistema da razão pura que não se restringe, no entanto, ao formalismo da Lógica clássica. Qual a diferença entre uma e outra? A Ciência da Lógica tem como objeto a Idéia no elemento puro abstrato do pensamento, isto é, a Idéia em-si e para-si. ${ }^{23}$ A Idéia em-si e para si é a razão pura infinita ou, como Hegel afirma no Conceito Geral da Lógica, é a representação de Deus na sua essência eterna, anteriormente à criação da natureza e de um espírito finito. $\mathrm{Na}$ apresentação de seu sistema filosófico na Enciciopédia, que consta da Lógica, da Filosofia da Natureza e da Filosofia do Espírito, Hegel nos dá uma definição dos termos lógica, natureza e espírito, bem como de sua relação. A lógica ou logicidade é a razão pura e infinita, a Idéia em-si e para-si. A Ciência da Lógica tem esta logicidade como objeto, logicidade esta que representa a racionalidade do mundo, na sua forma pura, enquanto Idéia. A Ciência da Lógica é, portanto, o estudo das determinações da Idéia. Faz parte da necessidade da Idéia - já que ela é substância e, ao mesmo tempo, sujeito - sua exteriorização. A exteriorização da Idéia nos dá a natureza. Faz parte igualmente da necessidade da Idéia a criação do universo espiritual que denota em Hegel o espírito (realidade humana coletiva, civilização) e sua criação (que podemos designar por Cultura). Há, na Idéia, um impulso de exteriorização, de se fazer mundo, criando, neste processo, um universo natural e espiritual onde sejam encontradas suas determinações racionais. A Idéia não é, entretanto, uma substância imóvel, ela perfaz um processo de saída de si e de constituição da natureza e do mundo espiritual como seu-outro. Alteridade que mantém suas determinações racionais, por um lado, e que, por outro, expõe esta racionalidade à contingência do mundo.

A Idéia como razão pura se exterioriza em natureza e espírito. Logo, as determinações da razão se encontrarão no mundo natural e também no mundo espiritual. Por outro lado, a Idéia só pode se exteriorizar em natureza e espírito porque contém em si a objetividade e a subjetividade. Isto não significa que os objetos do mundo natural ou do mundo espiritual são totalmente racionais. O processo de exposição da Idéia, de sua exteriorização, está, como Hegel nos diz a propósito da natureza "sujeito ao irracional da exterioridade". ${ }^{24} \mathrm{O}$ mundo, devido ao fato de ser exteriorização da razão, não a apresenta na sua pureza, mas lhe acrescenta o contingente, o arbitrário, o não-racional. A natureza é informada por regras racionais, mas existem aspectos na sua forma que são contingentes por estarem sujeitos, no dizer hegeliano, "a uma acidentalidade sem regra e sem freio". ${ }^{25} \mathrm{Da}$ mesma forma,

21 Hegel nos apresenta da seguinte forma o objeto da Lógica: "Deus tal como é na sua essência eterna, anteriormente à criação da natureza e de um espírito finito". S. L., I, p. 35. 
no mundo espiritual, também as criações de um povo não são inteiramente racionais. Como exemplo, podemos nos referir à consideração de Hegel na Filosofia do Direito que os Estados concretos não coincidem perfeitamente com a Idéia de Estado, ${ }^{26}$ isto é, ele está sujeito às imperfeições de tudo que é a exteriorização da Idéia. $\mathrm{Ou}$, os momentos de desrazão na História, momentos que, no dizer de B. Bourgeois, "não são lugar da universalização objetiva do espírito" : 27 estes momentos não racionais, "a dispersão, a repetição, a monstruosidade do devir do espírito, os povos abandonados pelo espírito, o mal irredutível ${ }^{128}$ fizeram sempre parte da civilização; não sendo, entretanto, momentos espirituais. Todavia o espírito, apesar destas "imperfeições da empiria", acaba sempre por se afirmar.

Hegel pretende restituir à Metafísica um papel fundamental na sua filosofia, e sua Ciência da Lógica cumpre este papel. As categorias da Lógica são as determinações da razão; as determinações da razão estão, por sua vez, presentes no ser, pois tudo o que é, é, ao menos potencialmente, racional. Desta forma, tendo como objeto de sua Ciência da Lógica uma razão dotada de conteúdo, Hegel analisa aí as determinações do que é. Hegel toma as estruturas racionais do ser como objeto de sua Ciência da Lógica.

A Lógica de Hegel não é, entretanto, o estudo do ser enquanto ser (pois não inclui o arbitrário, o contingente de toda exterioridade) mas o estudo do ser racional. Ela trata das categorias do lógos, neste sentido não é uma ciência do ser, mas uma ciência das determinações da razão. Mas, em conseqüência do fato de que, para Hegel, as categorias do ser são as categorias do lógos, a Lógica, ao tratar das categorias do lógos, trata conseqüentemente das categorias do ser, sendo, de certa forma, um resgate da Metafísica, cuja ausência da Filosofia era deplorada por Hegel.

Se a Lógica trata das determinações da razão, isto não significa que está tratando de algo puramente formal. A Ciência da Lógica trata das categorias da razão e, ao mesmo tempo, das categorias do ser. Dito de outra forma, ela é tanto uma lógica subjetiva, quanto uma lógica objetiva. $\mathrm{O}$ desenvolvimento mesmo deste texto nos mostra o processo de unificação entre estes dois termos: racionalidade subjetiva e racionalidade objetiva. O conceito, em cujo desenvolvimento consiste o conteúdo da Ciência da Lógica, não é puramente lógico, nem puramente real. Ele é o elemento puro de uma totalidade lógico-real, sendo também ele lógico-real e seu desenvolvimento perpassa tanto a lógica objetiva (Lógica do Ser e Doutrina da Essência), quanto à lógica subjetiva (Doutrina do Conceito). Desta forma, Hegel evita a separação entre sujeito e objeto, pois o elemento básico da Ciência da Lógica contém em si a objetividade e a subjetividade.

A Doutrina do Conceito, terceiro e último momento da Ciência da Lógica, trata da lógica subjetiva, porém traz em si seus momentos anteriores: a lógica objetiva, do ser e da essência. $O$ conceito traz em si o ser e a essência que foram supra-assumidos neste processo, bem como suas características. O conceito é substância:

\footnotetext{
$26 \mathrm{Ph}$. R., § 340.

27 BOURGEOIS, B. "Hegel et la Déraison dans l'Histoire", in: Logik und geschichte in hegels system. Frommann-Holz boog, 1989, p. 59.

28 Idem, Ibidem.
} 
nesta afirmação identificamos a presença da identidade a si e da permanência típicas da Lógica do Ser. A este elemento de permanência soma-se dialeticamente o movimento próprio da essência: a reflexão enquanto pôr e pressupor. A estrutura dual da essência que perpassa toda a obra desde a dupla essência/aparência se transforma, na efetividade, ${ }^{29}$ numa dualidade entre substancialidade e causalidade. Este é o último momento onde se confrontam as esferas do ser e da essência, como confronto entre substancialidade e causalidade: a substancialidade tem sua gênese na aparência, que é a positividade advinda do ser; a causalidade representa a estrutura da reflexão, própria da essência. O conceito supra-assume esta dualidade; ele é substância e, ao mesmo tempo, causa de si. O conceito é o sujeito lógico que, no seu automovimento, põe a objetividade, de forma a efetuar uma dedução do real a partir da explicitação dos momentos da lógica objetiva nele contidos.

A Doutrina do Conceito mostra a dedução da Idéia, partindo do conceito abstrato, ou do conceito de conceito, e chegando à objetividade. O conceito abstrato que se desdobra na objetividade, numa emergência das estruturas do ser que continha em si, dá origem, por fim, a Idéia, onde ser e pensar vem a constituir um todo único. A Idéia constitui o final de um processo de identificação progressiva entre a lógica subjetiva e a lógica objetiva. A Idéia é a expressão da identidade entre as estruturas lógicas do ser e as estruturas lógicas do pensamento. Todavia, existem coisas concretas no mundo cuja estrutura lógica não corresponde a uma estrutura racional. Nesses "rastros" não encontramos a Idéia enquanto esta identidade entre ser e lógos: "[...] todo efetivo só é na medida em que tem em si a Idéia e a exprime. $\mathrm{O}$ objeto, o mundo objetivo e subjetivo em geral, não deve simplesmente ser congruente com a Idéia, mas eles são eles mesmos a congruência do conceito e da realidade; a realidade que não corresponde ao conceito é simplesmente fenômeno, o subjetivo, contingente, arbitrário, que não é verdade" ${ }^{30}$ Hegel efetua aqui uma separação do que denomina realidade (Realität) em dois campos. De um lado temos a realidade que é a expressão da Idéia, ou seja, a realidade racional parte dela não expressa a racionalidade da Idéia. Este "lado" da realidade é contingente e arbitrário - ele existe, entretanto não é racional. No dizer hegeliano, ele é, porém não é verdadeiro.

A Idéia, enquanto unidade do conceito e da objetividade é a marca da racionalidade hegeliana. Dito de outra forma: só é efetivo - e, portanto, racional, já que "todo efetivo é racional e todo racional é efetivo" - o ser que for mediado pela razão. A "magia da dialética" hegeliana, enquanto projeto de unificação entre Lógica e Ontologia é, portanto, uma retomada da posição kantiana de constituição do mundo pelo sujeito, sem as limitações desta teoria. A coisa-em-si é trazida à consciência e as idéias da razão passam a engendrar conhecimento. Hegel pretende ampliar o espaço constitutivo do sujeito, englobando aí elementos da ação prática do homem. Tanto para o conhecimento dos objetos da natureza, quanto para a ação prática do homem na sua relação intersubjetiva vale o seguinte preceito: onde a realidade não corresponde ao conceito, temos apenas fenômeno (Erscheinung), brilho fugaz, sem consistência efetiva.

29 S. L., II, p. 246; W. L., II, p. 200.

30 S. L., III, p. 275; W. L., II, p. 464. 
Hegel opõe-se a separação entre ser/razão, objeto/sujeito, noumeno/fenômeno, alma/corpo; conseqüentemente, opõe-se também a separação da realidade em dois campos: uma realidade composta da natureza e suas leis e conexões internas, que é objeto de conhecimento; uma outra realidade, relacionada com o homem e suas criações, objeto apenas de crença ou opinião. Esta última é tão racional quanto a outra e também é objeto de conhecimento. A Ciência da Lógica, enquanto exposição das determinações da razão, o é também das determinações do ser racional, presente tanto na natureza, quanto no homem e nas suas construções.

Hegel constrói uma unidade entre o mundo natural e o mundo humano, pois ambos são informados pela mesma racionalidade; conseqüentemente, ambos são dados ao conhecimento. Não há, portanto, uma parte do mundo que pode ser conhecida pela consciência e outra que deve apenas ser concebida. Da mesma forma, a consciência não se relaciona com o mundo através do entendimento ou da razão de forma exclusiva. O entendimento e razão kantianos são amalgamados num mesmo processo de conhecimento, que consiste na apreensão do verdadeiro no seu automovimento, ou seja, na exposição da racionalidade do ser. 